\title{
Você tem fome de quê?
}

\section{o processo de ensino e aprendizagem de espanhol (E/LE) como língua estrangeira por meio da Cultura}

\author{
What are you hungry for? The process of learning and \\ teaching Spanish as a foreign language through Culture
}

\author{
Natália Araújo da Fonseca* \\ Denise de Andrade Santos Oliveira**
}

RESUMO: Este artigo tem como objetivo refletir sobre a importância da Cultura no processo de ensino e aprendizagem do espanhol como língua estrangeira (E/LE) por meio do diálogo entre as múltiplas linguagens, tais como literatura, música e pintura, uma vez que língua e cultura são indissociáveis (HYMES, 1972; DALPIAN, 1996; BROWN, 1994; DURÃO, 1999, 2002a, 2002b; FIORIN, 2005; DOURADO; POSHAR, 2010). Para isto, é proposto um trabalho interdisciplinar, entre as disciplinas de Artes e Língua Espanhola, permeado por um projeto didático-pedagógico a ser desenvolvido com o objetivo de fazer o aprendiz se tornar um cidadão reflexivo não apenas sobre os bens culturais da LE, mas também sobre a cultura da sua língua materna (LM).

PALAVRAS-CHAVE: Língua espanhola. Cultura. Interdisciplinaridade.

ABSTRACT: This paper aims to reflect about how is important the Culture in the teaching and learning process of the Spanish as a foreign language through the dialogue among multiples languages, such as literature, music and masterpiece, once language and culture are inseparable (HYMES, 1972; DALPIAN, 1996; BROWN, 1994; DURÃO, 1999, 2002a, 2002b; FIORIN, 2005; DOURADO; POSHAR, 2010). It suggests an interdisciplinary project, between the Spanish and Art subjects,

\footnotetext{
* Mestrado em Letras Estrangeiras Modernas pela Universidade Estadual de Londrina (UEL). Contato: natalia.es.uel@gmail.com.

** Mestrado em Letras Estrangeiras Modernas pela Universidade Estadual de Londrina (UEL). Contato: deniandrade@hotmail.com.br.
} 
which purpose is instigate the students to become a citizen that can reflect about the cultural aspects of the foreign language and about their mother language.

KEYWORDS: Spanish language. Culture. Interdisciplinary.

\section{Introdução}

A riqueza de uma língua é proveniente não só dos aspectos gramaticais e lexicais que a constituem, mas também dos elementos culturais, históricos e sociais, os quais Ihe conferem sentido e significado. Diante disso, concordamos com (HYMES, 1972; DALPIAN, 1996; BROWN, 1994; DURÃO, 1999, 2002a, 2002b; FIORIN, 2005; DOURADO; POSHAR, 2010), uma vez que esses autores consideram língua e cultura indissociáveis.

Partimos da ideia de que a língua é como um alimento oriundo de uma receita, que pode vir a sofrer adaptações regionais ou de um país para outro, de acordo com a criatividade e/ou a necessidade daquele que a produz. Sob esta perspectiva, consideramos que a língua alimenta não só a comunicação diária, mas também a alma, o intelecto, a personalidade e a cultura.

A língua, além de instrumento de comunicação é, sobretudo, instrumento de (trans)formação social e humana. Desta forma, objetivamos, neste trabalho, sugerir atividades didático-pedagógicas que apresentem uma proposta para 0 ensino de espanhol como língua estrangeira ( $E / L E)$ que vá muito além do linguístico.

Nessa perspectiva de ensino, a Cultura e os bens que a constituem assumem protagonismo e, assim, a literatura, a pintura e a música se convertem em recursos didáticos para fazer com que os estudantes tenham contato com o universo das Artes e, por meio delas, possam conhecer outras maneiras de ver e interpretar o mundo.

Deste modo, dentre as diversas manifestações artísticas ${ }^{1}$ existentes, optamos por trabalhar com obras pertencentes aos artistas latino-americanos. Por intermédio delas, objetivamos que os alunos possam refletir sobre as

\footnotetext{
${ }^{1}$ Ao longo deste artigo, utilizamos os termos "manifestações artísticas", "expressões artísticas" e "múltiplas linguagens" para referirmos à literatura, música e pintura, uma vez que nossa proposta didádico-pedagógica visa estabelecer um diálogo entre os textos verbais (música e poema) e imagéticos (pintura).
} 
temáticas retratadas, comparar a realidade brasileira com a dos demais países hispânicos e, assim, (re)pensar sua identidade enquanto sujeitos latinoamericanos.

Acrescentamos que, com relação às atividades, buscamos trabalhar a interdisciplinaridade, estabelecendo, assim, um diálogo com a disciplina de Artes, a fim de explorar as habilidades orais e escritas do aprendiz em consonância com suas habilidades artísticas e criativas.

Esse intercâmbio entre as duas disciplinas será relevante, pois o ensino interdisciplinar passa a ser aqui uma forma de aprendizagem em que os discentes possam obter conhecimento de maneira compartilhada por intermédio de dois docentes que lhes apresentarão os conteúdos de maneiras diferentes (re) construindo a sua aprendizagem e sua maneira de pensar (FREIRE, 1987).

Diante deste cenário, este artigo está dividido da seguinte maneira: primeiramente apresentamos uma breve reflexão sobre a importância da cultura e suas mais variadas definições.

Na sequência, discorremos sobre a importância da língua e cultura na formação da nossa identidade. Em seguida, discutimos sobre o papel do professor no processo de ensino e aprendizagem de uma LE diante do trabalho com os aspectos culturais.

Após a teoria, sugerimos uma proposta didático-pedagógica interdisciplinar a fim de que o professor possa fazer uso das múltiplas linguagens no intuito de possibilitar um ensino integrador entre língua e cultura.

Por fim, apresentamos nossas considerações finais, tecendo algumas reflexões sobre o trabalho com a Cultura nas aulas de LE.

\section{Cultura: em busca de uma definição consensual}

A atual literatura abarca diversas definições sobre cultura e, encontrar a que melhor se ajuste à concepção subjacente a este artigo não é uma tarefa fácil, uma vez que elas se complementam. Diante dessa amplitude, apresentamos diferentes concepções ou definições de cultura a fim de, posteriormente, explicitar a que se adapta aos nossos fins. 
Marconi e Presotto (2001) apresentaram um panorama histórico que abarca mais de 160 definições sobre este termo e afirmam que ainda não há consenso sobre o exato significado dele. Desta forma, muitos outros ainda poderão surgir futuramente.

Palavra de origem latina, o vocábulo cultura era, inicialmente, atrelado ao cultivo da terra. Com a evolução do conceito, a partir da segunda metade do século XVI, a palavra adquiriu um sentido figurado, referindo-se ao cultivo do espírito e do desenvolvimento do intelecto (DOURADO; POSHAR, 2010).

Tylor (2010, p. 23) apresentou, na antropologia, uma das primeiras definições mais formais sobre esse conceito apregoando-o como sendo "todo aquele complexo no qual estão inclusos os conhecimentos, as crenças, a arte, a moral, a lei, os costumes e outras aptidões e hábitos adquiridos pelo homem como membro da sociedade".

Para corroborar a ideia supracitada, utilizamos as palavras de Ferreira e Sanches (2005, p. 203), que definem cultura como "tudo aquilo que faz parte da vida e das características de um povo: língua, valores espirituais e materiais, roupas, músicas, literatura, festas, artesanato, leis, momentos de lazer."

Convergimos com o ponto de vista de Durão, Ferreira e Pérez (2006, p. 182), visto que estes autores assinalam que

a cultura revela características da sociedade em que se vive, pela qual é determinada de acordo com o processo histórico vivido por uma nação. Por isso, pode-se dizer que a cultura é tudo o que faz parte da vida e das características de um povo.

De acordo com o entender de Oliveras Vilaseca (2000, p.11), cultura pode classificar-se como

[...] o meio de comunicação do homem e [que] não existe nenhum aspecto da vida humana a que a cultura não esteja relacionada. Representa a personalidade dos membros de uma comunidade. Tem muita relação com a maneira como as pessoas se expressam emocionalmente, a forma de pensar, de se movimentar, de resolver problemas [...]. 
Apesar das várias definições existentes até o presente momento, alguns estudiosos ainda sentiram a necessidade de explicar o termo cultura de maneira mais categórica e específica. Kramsch (1988), por exemplo, subdividiu-a em: "cultura" (com grifo no "c" minúsculo) e "Cultura" (com grifo no "C" maiúsculo).

A primeira refere-se aos eventos do dia a dia de uma comunidade (como a maneira de cumprimentarmos uma pessoa - como um aperto de mão, beijo no rosto, a forma como nos vestimos, os gestos que usamos para nos comunicar).

Já a segunda, ou seja, com "C" maiúsculo, é utilizada para classificar os fenômenos culturais associados ao âmbito artístico e intelectual (como as obras de artes - pinturas, esculturas -, os monumentos arquitetônicos, as obras literárias).

Neste estudo, optamos por trabalhar com a Cultura, sendo aqui representada pela literatura, música e pintura latino-americanas para que, a partir dessas manifestações artísticas, possamos explorar os temas históricos, sociais e culturais que elas retratam, a fim de que os alunos conheçam outros olhares sobre os aspectos que constituem a realidade do nosso continente.

\section{Língua, cultura e identidade no processo de ensino e aprendizagem de} LE

$\mathrm{Na}$ seção anterior, apresentamos algumas definições sobre o termo cultura, segundo a concepção de vários estudiosos. Explicitamos, também, de acordo com a classificação de Kramsch (1988), a diferença entre Cultura e cultura. Contudo, neste tópico, buscaremos discorrer sobre a estreita relação entre língua e cultura e como elas podem influenciar diretamente nossa identidade.

Conforme as palavras de Byram (1989, p. 51) a língua, dentro do contexto de ensino e aprendizagem, "deveria ser usada como um meio, não para resolver problemas, mas para ensinar e aprender sobre o povo e a cultura associados a ela." 
Scherre (2005, p. 10) complementa os dizeres do autor supracitado e acrescenta que língua e cultura estão intimamente relacionadas à identidade

As línguas humanas são, em verdade, mais do que excelentes instrumentos de comunicação. São, também, reflexo da cultura de um povo. São, além disso, parte da cultura de um povo. São ainda mais do que isto: são mecanismos de identidade. Um povo se individualiza, se afirma e é identificado em função de sua língua.

Igualmente, Kramsch (1998, p. 65) salienta que

as línguas expressam e simbolizam realidades culturais. As pessoas expressam diferentes fatos e ideias através da linguagem ao se referirem a um conhecimento de mundo comum compartilhado. A maneira com que expressam suas experiências é compreendida pelo grupo a que pertencem e os falantes identificam a eles mesmos e aos outros através do uso da língua, que é vista como um símbolo de identidade social.

De acordo com o pensamento dos autores, fica clara a relação que há entre língua e cultura e suas influências em nossa identidade, visto que a cultura se reflete na língua e ambas são elementos constituintes da nossa identidade. Nesse sentido, Bakhtin (2002, p. 13) assevera que "[...] é na relação de alteridade que os indivíduos se constituem. [...] constituímo-nos e nos transformamos sempre através do outro."

O contexto de ensino de uma LE oportuniza, aos alunos, uma aproximação com outras línguas e culturas, possibilitando que a identidade deles seja constantemente (res)significada, uma vez que estão em permanente contato com uma pluralidade de vozes, concepções e formas de agir sobre 0 mundo.

Ao compartilhamos da mesma visão dos autores aqui apresentados, elaboramos uma proposta didático-pedagógica que tem como principal objetivo ensinar o espanhol por meio da literatura, música e pintura latino-americanas, as quais abordam a mesma temática: "a fome" nas suas mais diversas manifestações, ou seja, no sentido literal "fome de comida" e no sentido metafórico "fome de Cultura". 
Nessa perspectiva, utilizaremos a música "Comida", do grupo brasileiro Titãs, o poema "Hambre", da escritora chilena Sylvia Rojas Pastene e a tela intitulada "El Hambre", pertencente ao pintor equatoriano Oswaldo Guayasamín.

Por meio do diálogo entre as obras, almejamos explorar os aspectos sociais, históricos e culturais que elas contemplam e, assim, fazer os discentes refletirem e discutirem sobre essas temáticas, além de compararem os temas abordados nas obras com a realidade brasileira.

Por conseguinte, esperamos fazer com que os alunos de E/LE (re)pensem sua identidade latino-americana por meio dessas obras, para que sejam conscientes de que, mesmo tendo o português como língua materna, somos latino-americanos e integramos esse continente. Além do mais, compartilhamos com os demais países hispânicos um passado colonial semelhante, sendo parte e resultado de um mesmo processo histórico.

\section{Professor: um mediador cultural}

Possibilitar aos alunos o contato com a "cultura do outro" requer, por parte dos docentes, uma série de cuidados. O primeiro deles deve-se ao fato de que seus aprendizes estão em formação.

Por esta razão, o educador deve compreender que ele não pode influenciar seus alunos a pensarem da mesma maneira que a sua, mas sim estimulá-los a desenvolver sua própria opinião crítica sobre os temas discutidos em sala.

Em outras palavras, o professor tem que buscar imparcialidade, em vez de manipular ou influenciar o pensamento e a opinião dos alunos sobre a cultura estrangeira.

Lilova (2010) contribui sobre este aspecto ao apregoar que o docente deve ter um papel de orientador e organizador do trabalho em sala, enquanto Benito $(2012$, p. 497) salienta que: 
um "mediador cultural", em um agente que opera entre várias culturas; chegando inclusive a poder ser considerado como diplomata, por ter posição estratégica entre as culturas.

Segundo Benito (2012) e Santamaría Martínez (2008), o professor, como agente operacional, precisa levar os aprendizes a contrastar a cultura materna com a estrangeira e, acima de tudo, fazê-los participar ativamente em suas interpretações, para que consigam adaptar-se a uma realidade linguística e social diferente da sua e, assim, captar os significados imbuídos em todos os elementos que constituem a cultura de um país.

Para facilitar a aprendizagem, o docente pode mostrar, por exemplo, que o tango argentino não é melhor ou pior que o samba, ou que a culinária espanhola não é mais ou menos importante que a brasileira, que os mexicanos, ao celebrarem o dia dos mortos com festas e venda de doces em formato de caveiras e esqueletos, respeitam esse feriado tanto quanto nós, mas que aprenderam a celebrá-lo de maneira diferente.

O professor poderá comparar e refletir com os seus alunos as belezas e particularidades de cada cultura fazendo-os pensar sobre o que podem aprender com cada uma delas.

Deste modo, ao apresentar diferentes tipos de Culturas/culturas que permitam-lhes desenvolverem seu conhecimento, o docente poderá utilizar variados materiais (filmes, pinturas, músicas, textos literários, histórias em quadrinho, reportagens, propagandas, etc.) que se encontram disponíveis tanto no formato impresso quanto em fontes digitais.

Ademais, reforçamos, mais uma vez, que a interdisciplinaridade pode ter um papel fundamental no processo de construção do conhecimento, haja vista que o professor de LE precisa ser consciente sobre a importância de dialogar com os docentes de outras disciplinas, para que possam então se aprofundar nos assuntos que mais se relacionam com as outras áreas do conhecimento.

Sendo assim, destacamos que o professor precisa ser cônscio do papel que desempenha, pois, mais do que outrora considerado um mediador de conhecimento, deve assumir o papel de "apresentador" do novo, em que o 
aluno terá que aprender a entender e a desbravar o outro na busca de (re)significar sua identidade e estreitar laços com o que, a priori, lhe é distante, diferente, alheio, estrangeiro.

\section{Mãos à obra: propostas de atividades didático-pedagógicas}

As propostas que apresentamos a seguir consistem na utilização das múltiplas linguagens (textos verbais e imagéticos) como ferramenta de ensino da língua e cultura espanhola. Nessa seara, por meio das atividades, objetivamos fazer com que os alunos pratiquem a Expressão Oral (EO) em LE ao utilizarem estruturas comunicativas para opinar, bem como demonstrar acordo ou desacordo sobre os temas abordados nas obras sugeridas.

É o momento de colocar em prática o que Kramsch (1998) e Scherre (2005) defendem, ou seja, utilizar a LE em aprendizagem para se expressarem sobre as realidades culturais dos países em questão, compartilhando ideias, opiniões, experiências de vida podendo identificar-se ou não com o outro.

Nossa proposta não tem o intuito de trabalhar com a língua de maneira tradicional, mas utilizá-la mediante atividades que possam motivar os alunos a buscar mais informações sobre a LE, objeto de estudo (CALLEGARI; FERNÁNDEZ, 2010).

Conforme mencionamos na introdução deste artigo, buscamos promover o diálogo entre o ensino da língua espanhola e a disciplina de Artes, a fim de desenvolver um projeto interdisciplinar, pois segundo as Diretrizes Curriculares Nacionais da Educação Básica do Estado do Paraná:

As disciplinas escolares não são herméticas, fechadas em si, mas, a partir de suas especialidades chamam umas às outras e, em conjunto, ampliam a abordagem dos conteúdos de modo que se busque, cada vez mais, a totalidade, numa prática pedagógica que leve em conta as dimensões científica, filosófica e artística do conhecimento (PARANÁ, 2008, p. 27).

Deste modo, como essas sugestões didáticas requerem explicações e pesquisas, tanto por parte do professor como do aluno, aconselhamos desmembrá-las e trabalhá-las em três aulas de, no mínimo, cinquenta minutos 
para que haja uma boa exploração das atividades.

Se por ventura o docente dispuser de menos tempo, elas podem ser aplicadas em mais de três aulas e ser adequadas de acordo com o tempo disponível. Salientamos que as sugestões didáticas se dão de maneira sequencial e metódica.

Público alvo: alunos do ensino médio.

Duração das atividades: três aulas de Língua Espanhola e uma aula de Artes.

\section{Aula 1: Você tem fome de quê?}

Objetivo geral: desenvolver o pensamento crítico e reflexivo do aluno.

Objetivos específicos:

- praticar a Expressão Oral (EO) na LE por meio das estruturas linguísticas utilizadas para opinar, bem como expressar acordo e/ou desacordo;

-discutir os vários significados que a palavra "fome" pode adquirir segundo o contexto em que se encontre inserida;

Materiais necessários: data-show, televisão pen-drive, ou fotos impressas, rádio, $C D$, quadro negro, computadores.

Atividade 1: $\quad$ Essa primeira atividade tem como intuito iniciar o projeto de uma forma mais dinâmica. Deste modo, comece dividindo os alunos em pequenos grupos. Em seguida, apresente-lhes vários fragmentos de músicas ${ }^{2}$ de cantores brasileiros que têm como temática a comida. 0 objetivo é que eles descubram quem é o cantor e qual é o título da canção. Dê um tempo para que possam refletir sobre as músicas e escrever seus possíveis títulos. Após este momento, faça a correção da atividade. Por último, ganha o jogo o grupo que tiver o maior número de acertos.

Atividade 2: Inicie esta atividade voltando à última música apresentada ("Comida" do grupo Titãs) e peça para que os alunos escutem-na na íntegra. Após ouvirem-na, discuta sobre a relação que há entre o título e a letra.

Sugestão de perguntas para incitar discussão:

- ¿Por qué creen que el título de la canción es "Comida"?

- ¿Cuál es el tipo de "hambre" que el grupo retrata el su canción?

\footnotetext{
2 Músicas: Não é proibido (Marisa Monte), Eu quero é mais (Sandy e Junior), Chocolate (Tim Maia), Farofa (Silvio Brito), Yes, nós temos banana (Carmen Miranda), Caviar (Zeca Pagodinho), Feijoada Completa (Chico Buarque de Holanda), Comida (Titãs).

${ }^{3}$ Disponível no site: https://www.letras.mus.br/titas/91453/
} 


\begin{tabular}{|l|l|}
\hline - ¿Están de acuerdo con lo que el grupo brasileño plantea en su \\
canción? Razonen su respuesta. \\
Apesar de ser uma música brasileira, ou seja, ser na língua materna \\
dos aprendizes o objetivo aqui é que eles interpretem-na, porém se \\
expressem na LE alvo, a fim de praticar o léxico, a pronúncia, etc. \\
Aproveite a pergunta do refrão da letra e faça o mesmo \\
questionamento: Vocês têm fome de quê? \\
É interessante fazer a mesma pergunta em língua espanhola e \\
mostrar-Ihes o modelo de como iniciariam suas respostas: \\
¿De qué tienes hambre? \\
Tengo hambre de... \\
\hline $\begin{array}{l}\text { Atividade 3: } \\
\text { vários textos imagéticos que remetem a temas como: justiça, paz, } \\
\text { igualdade, liberdade, arte, cultura entre outros aspectos que façam } \\
\text { parte do assunto contemplado. } \\
\text { Vá apresentando as imagens e questionando-os sobre o que elas } \\
\text { representam não só para eles, mas também para a sociedade de um } \\
\text { modo geral. Este é um momento para desenvolver a reflexão dos } \\
\text { discentes, objetivando que possam, por meio dos questionamentos, } \\
\text { compreender as problemáticas sociais }{ }^{4} \text {. } \\
\text { A fim de que os alunos possam emitir sua opinião em espanhol, } \\
\text { apresente-lhes algumas estruturas linguísticas para expressar opinião: } \\
\text { Creo que.../Pienso que.../Me parece que... } \\
\text { A proposta aqui é mostrar que precisamos ter fome não só de comida, } \\
\text { mas também de elementos que garantam o bem estar social para } \\
\text { todos e não apenas para uma minoria privilegiada. }\end{array}$ \\
\hline
\end{tabular}

\section{Aula 2: Hambre na perspectiva de Sylvia Rojas Pastene}

Objetivo geral: desenvolver o pensamento crítico e reflexivo do aluno.

Objetivos específicos:

- ler e interpretar o poema Hambre e refletir sobre o assunto contemplado;

-praticar a Expressão Oral (EO) na LE por meio das estruturas linguísticas utilizadas para opinar, entre outras.

- discutir sobre a caótica situação de miséria que acomete parte da população latinoamericana, principalmente aqueles que vivem à margem da sociedade (indígenas, negros, moradores da periferia, etc.);

- Materiais necessários: poema impresso, se necessário, quadro negro e giz.

Atividade 1: $\quad$ Inicie fazendo uma breve retomada do que foi apresentado e discutido

\footnotetext{
${ }^{4}$ Neste momento, é interessante que o professor pergunte aos alunos se acreditam que a maneira de pensar, agir e ver dos jovens hispânicos no que se refere aos temas como a fome de justiça, arte, cultura, igualdade e liberdade se assemelha ou diferencia do jovem brasileiro.
} 
o processo de ensino e aprendizagem de espanhol (E/LE) como língua estrangeira por meio da Cultura

\begin{tabular}{|c|c|}
\hline & \\
\hline Atividade 2: & $\begin{array}{l}\text { Comece a atividade distribuindo aos aprendizes o poema Hambres, } \\
\text { pertencente à escritora chilena Sylvia Rojas Pastene. Em seguida, faça } \\
\text { a leitura do texto com eles. O objetivo aqui é fazer com que os alunos } \\
\text { compreendam a mensagem do poema. Após este momento, divida-os } \\
\text { em pequenos grupos e peça-Ihes para discutir sobre o texto para que, } \\
\text { posteriormente, possam compartilhar suas opiniões com o restante do } \\
\text { grupo. } \\
\text { Sugestão de perguntas para incitar discussão: } \\
\text { - ¿Qué tipo de "hambre"la escritora se refiere en su poema? } \\
\text { - ¿Creen que hay alguna relación entre la canción "Comida" del grupo } \\
\text { Titãs y el poema de Pastene? ¿Cuál? } \\
\text { - ¿Cómo describirías física y psicológicamente el "yo lírico" del poema? } \\
\text { - Si fuéramos a identificar el "yo lírico" que Sylvia describe en nuestra } \\
\text { sociedad, ¿dónde lo encontraríamos y qué personas serían? }\end{array}$ \\
\hline Atividade 3: & $\begin{array}{l}\text { Ao finalizarem a discussão comente sobre a situação de miséria que } \\
\text { acomete pessoas do mundo todo. Peça para que pensem sobre o } \\
\text { motivo que leva grande parte da população negra e indígena ser a que } \\
\text { mais sofre com os problemas sociais, tendo que viver em condições } \\
\text { desumanas. } \\
\text { Se necessário, para que os alunos possam se aprofundar nessa } \\
\text { discussão, peça ao professor de História que explique e/ou retome o } \\
\text { conteúdo sobre o processo de colonização na América Latina, } \\
\text { enfatizando as suas consequências para o nosso continente nos dias } \\
\text { atuais. }\end{array}$ \\
\hline Tarefa: & $\begin{array}{l}\text { A fim de proporcionar uma maior autonomia aos alunos, é } \\
\text { interessante que o professor solicite aos aprendizes uma pesquisa } \\
\text { sobre o contexto social em que o poema foi produzido, no intuito de } \\
\text { associar o texto com os acontecimentos que podem estar relacionados } \\
\text { à temática. } \\
\text { Alertamos que, para otimizar o tempo da aula, a busca do vocabulário } \\
\text { desconhecido pode ser dada como tarefa. }\end{array}$ \\
\hline
\end{tabular}

Aula 3: Hambre (1996) de Sylvia Rojas Pastene versus El Hambre (1996) de Oswaldo Guayasamín

Objetivo geral: desenvolver o pensamento crítico e reflexivo do aluno.

Objetivos específicos:

- analisar e interpretar a tela "El Hambre" e refletir sobre o tema retratado;

- praticar a Expressão Oral (EO) na LE por meio das estruturas lingüísticas utilizadas

${ }^{5}$ Disponível no site: http://bligoo.com/media/users/0/10252/images/Guayasamin.jpg 
para opinar, demonstrar acordo e/ou desacordo.

Material necessário: data-show ou aparelho projetor.

A tela poderá ser produzida em folhas de papel sulfite ou telas específicas para pintura. Para cada proposta é necessário adaptar os outros materiais: lápis de cor, tinta, giz de cera, etc.

Atividade 1: $\quad$ Siga o mesmo procedimento das aulas anteriores, isto é, antes de iniciar uma nova proposta, faça com os alunos uma revisão do que foi estudado.

Atividade 2: $\quad$ Inicie a atividade 2 apresentando-Ihes a tela do pintor equatoriano Oswaldo Guayasamín, cujo título também se denomina "El Hambre $^{6 \prime \prime}$.

Auxilie-os na interpretação da tela e verifique o que pensam que ela representa. Ao trabalhar com a leitura imagética da obra de Guayasamín, explore o máximo de elementos possíveis (as cores, os traços do artista, as expressões das personagens, entre outros aspectos).

Sugestão de perguntas sobre a pintura "El Hambre":

- ¿Qué les parece que Guayasamín retrata en su pintura?

- De acuerdo con las expresiones (rostro, cuerpo), ¿qué creen que los personajes están sintiendo?

- ¿Por qué piensan que el artista utilizó esos colores para retratar a los personajes?

- ¿Cuál es la relación que el cuadro establece con el poema de Pastene?

Pergunte-lhes também se consideram que os problemas evidenciados nas expressões artísticas são comuns no Brasil.

Sugestões de perguntas:

- ¿Les parece que el tema que Pastene trata en su poema también es común en Brasil? ¿Por qué?

- ¿Por qué creen que hay muchas personas que viven en situaciones precarias, principalmente en los países latinoamericanos?

Atividade 3: $\quad$ Para encerrar o estudo cultural sobre o assunto proposto, explique aos discentes que, como atividade final, eles produzirão com o professor de Artes, uma tela cujo tema principal seja "Fome". Nela, os alunos poderão expressar, de acordo com o ponto de vista de cada um, quais problemáticas desejam explorar, visto que a atual realidade do nosso país nos oferece várias possibilidades de conteúdos que se enquadrariam em nossa proposta.

Caso o professor de Artes não possa desenvolver esta última etapa do projeto em consonância com a disciplina de Espanhol, utilize

\footnotetext{
${ }^{6}$ Disponível no site: http://bligoo.com/media/users/0/10252/images/Guayasamin.jpg
} 


\begin{tabular}{|l|l|}
\hline mais uma aula de seu cronograma para que os aprendizes possam \\
elaborar suas telas no delinear das aulas. \\
Pensando que as expressões artísticas e a cultura devam ser \\
(com)partilhadas com todos, proponha, para a direção da escola, \\
que os trabalhos dos alunos possam ser expostos no pátio, para que \\
os outros discentes e docentes tenham a oportunidade de vê-las e \\
interpretá-las. \\
Juntamente com as telas dos alunos sugerimos que, na exposição, \\
haja um espaço reservado em que possa ser colocado o poema de \\
Pastene, a tela de Guayasamín e as letras das músicas utilizadas no \\
projeto, para que todos possam saber quais foram as fontes que \\
inspiraram os aprendizes no processo de elaboração de suas \\
produções (orais e escritas).
\end{tabular}

\section{Considerações Finais}

Iniciamos este artigo evidenciando que o ensino de uma língua está atrelado aos aspectos extralinguísticos e que devemos considerá-los essenciais, uma vez que a língua é viva e está repleta de cultura, tendo em vista que compreender as diferenças do outro nos torna mais complacentes e reflexivos sobre outras realidades sociais e culturais.

Posteriormente, discorremos sobre algumas definições do termo cultura, a importância da língua e dos bens culturais na (res)significação da nossa identidade, além de refletirmos sobre o papel do docente no processo de ensino e aprendizagem da E/LE ao trabalhar com a Cultura/cultura.

Deste modo, à luz das teorias apresentadas, sugerimos a proposta de um projeto, cujo objetivo era o desenvolvimento de um trabalho interdisciplinar em que alunos e professores de Língua Espanhola e Artes pudessem partilhar do ensino em que a leitura e interpretação das músicas, poema e tela os fizessem (re)pensar sobre uma realidade social que foi e/ou é comum aos países latino-americanos.

Além disso, ao ter acesso a Cultura por intermédio do projeto pedagógico sugerido, os aprendizes podem produzir a sua própria obra de arte, tornando-se também parte integrante deste processo, compartilhando-a com a 
comunidade escolar, no intuito de promover novas reflexões, tanto sobre os bens culturais quanto sobre os aspectos sociais que nos cercam.

Em conformidade com o que propomos inicialmente neste trabalho, de que língua e cultura são indissociáveis, acreditamos que essa integração só trará contribuições aos aprendizes, pois a Cultura alimentará tanto o seu intelecto, como também sua alma, seu espírito e sua criatividade.

Do mesmo modo que temos a necessidade biológica de alimentar nosso corpo, precisamos, sobretudo, incitar no aprendiz a necessidade de nutrir-se, constantemente, com alimentos que saciem sua fome de conhecimento. 


\section{Referências}

BAKHTIN, Mikhail. Marxismo e filosofia da linguagem. São Paulo: Hucitec Annablume, 2002.

BENITO, Ana Belén García. La competencia intercultural y el papel del profesor de lenguas extranjeras. 2012. Disponível em:<http://cvc.cervantes.es/ ensenanza/biblioteca_ele/asele/pdf/19/19_0493.pdf>. Acesso em: 7 abr. 2014.

BROWN, Douglas H. Principles of language learning and teaching. 4. ed. New Jersey: Prentice Hall Regents, 1994.

BYRAM, Michael. Cultural studies in foreign language education. Clevedon: Multilingual Matters, 1989.

CALLEGARI, Marília Vasques; FERNÁNDEZ, Gretel Eres. Estratégias motivacionais para aulas de língua estrangeira. São Paulo: Ed. Nacional, 2010.

DALPIAN, Laurindo. A língua e o acesso à cultura. Signos, Lajeado, Ano 17, n. 22, p. 49-54, 1996.

DOURADO, Maura Regina; POSHAR, Heliane Andrade. A Cultura na educação linguística no mundo globalizado. In: SANTOS, Percília; ALVAREZ, Maria Luisa Ortíz. Língua e cultura no contexto de português língua estrangeira. São Paulo: Pontes, 2010. p. 33-52.

DURÃO, Adja Balbino de Amorim Barbieri. A importância da explicitação de matizes culturais particulares no ensino de língua estrangeira. Signum, Estudos da Linguagem, Londrina, v.2, p.139-154, 1999.

. É preciso conhecer hábitos culturais para falar bem uma língua estrangeira?. Folha Nossa, Rolândia, 25 jul. 2002a. p. 6.

. Língua e cultura: uma relação em espelho. Folha Nossa, Rolândia, ago. 2002b. p.6.

DURÃO, Adja Balbino de Amorim Barbieri; FERREIRA, Cláudia Cristina; PÉREZ, Pedro Benítez. ¿Por qué trabajar con la competencia sociocultural en la clase de E/LE? In: CONGRESO INTERNACIONAL DE ASELE, 7., 2006, Logroño. Anais... Cáceres: Instituto Cervantes, 2006.

FERREIRA, Cláudia Cristina; SANCHES, Geane Maria Marques Branco. La comunicación no verbal y el proceso de enseñanza/aprendizaje de español como lengua extranjera. In: SIMPOSIO DE DIDÁCTICA DE ESPAÑOL PARA EXTRANJEROS, 2., 2005, Rio de Janeiro. Anais... Rio de Janeiro: Instituto Cervantes, 2005.

FIORIN, José Luiz. Há vínculos necessários entre língua. Pensamento e cultura? In: XAVIER, Antonio Carlos; CORTEZ, Susana (Org.). Conversas com linguístas: virtudes e controversias da lingüística. São Paulo: Parábola, 2005. p. 72-76. 
FREIRE, Paulo. Pedagogia do oprimido. Rio de Janeiro: Paz e Terra, 1987.

HYMES,Dell. On communicative Competence. In: PRIDE, J.B.; HOLMES, J. (Org.). Sociolinguistics. Harmondsworth: Penguin, 1972. p. 269-285.

KRAMSCH, Claire. Language and Culture. Oxford: Oxford University Press, 1998.

. The cultural discourse or foreign language textbooks. In: SINGERMAN, A. (Ed.). Toward a new integration of language and culture. Middlebury, VT: Northeast conference on the Teaching of Foreign Languages, 1988. p. 63-88.

MARCONI, Marina de Andrade; PRESOTTO, Zélia Maria Neves. Antropologia: uma introdução. São Paulo: Atlas, 2001.

LILOVA, Nadejda. Abordagem intercultural no contexto búlgaro. In: SANTOS, Percilia; ÁLVAREZ, Maria Luisa Ortíz (Org.). Língua e cultura no contexto de português língua estrangeira. São Paulo: Pontes, 2010. p. 87-100.

OLIVERAS VILASECA, Ángels. Hacia La competencia intercultural en el aprendizaje de una lengua extranjera: estudio del choque cultural y los malentendidos. Barcelona: Edinumen, 2000.

PARANÁ. Secretaria de Estado da Educação. Diretrizes curriculares da educação básica: língua estrangeira moderna. Curitiba, 2008.

SANTAMARÍA MARTÍNEZ, Rocío. La competencia sociocultural en el aula de español 12/le: una propuesta didáctica. 2008. 543 f. Tese (Doutorado) Facultad de Humanidades, Comunicación y Documentación, Universidad Carlos III de Madrid, Madri, 2008.

SCHERRE, Maria Marta Pereira. Doa-se lindos filhotes de poodle: variação linguística, mídia e preconceito. São Paulo: Parábola Editorial, 2005.

TYLOR, Edward Burnett. Primitive Culture: Researches into the development of mythology, philosophy, religion, art and custom. Cambridge: Cambridge University Press, 2010. 